\title{
Evaluation OF CARbon DiOXIDE SENSORS FOR INDOOR AIR QUALITY MONITORING
}

\author{
Adnan Masic, Dzevad Bibic, Boran Pikula \& Sanela Klaric
}
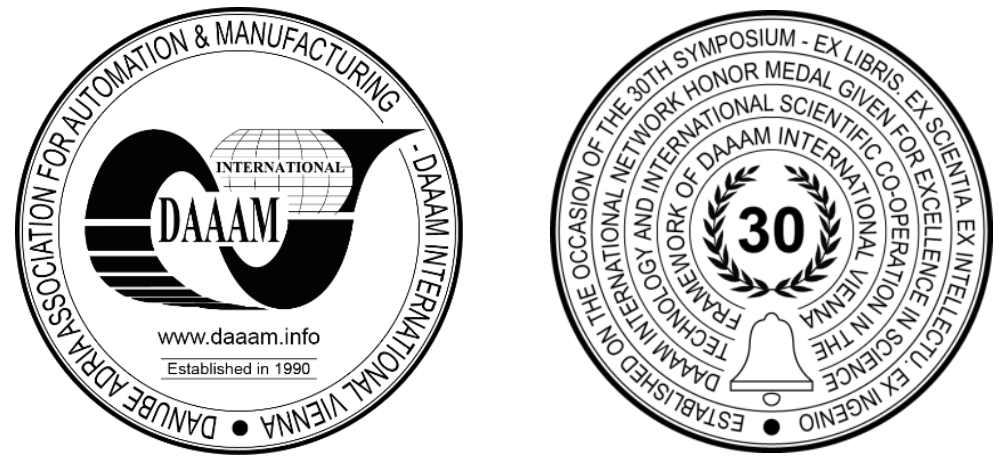

This Publication has to be referred as: Masic, A[dnan]; Bibic, D[zevad]; Pikula, B[oran] \& Klaric, S[anela] (2019). Evaluation of Carbon Dioxide Sensors for Indoor Air Quality Monitoring, Proceedings of the 30th DAAAM International Symposium, pp.0457-0459, B. Katalinic (Ed.), Published by DAAAM International, ISBN 978-3-902734-22-8, ISSN 1726-9679, Vienna, Austria

DOI: $10.2507 / 30$ th.daaam.proceedings.061

\begin{abstract}
Carbon dioxide $\left(\mathrm{CO}_{2}\right)$ is important factor of indoor air quality. In this paper we evaluate several $\mathrm{CO}_{2}$ sensors of latest generation. All sensors work on the same principle: nondispersive infrared (NDIR) detection. The sensors were evaluated in the campaign that lasted for several months. Good agreement between all sensors was observed, despite different construction, factory calibration and price. Finally, inexpensive method is proposed for continuous measurement of indoor concentrations of $\mathrm{CO}_{2}$.
\end{abstract}

Keywords: Carbon dioxide; Sensors; NDIR; Indoor air quality; Calibration.

\section{Introduction}

Measurement of concentration of carbon dioxide $\left(\mathrm{CO}_{2}\right)$ in the air is very important in many areas: from food production to the indoor air quality assessment and control [1], [2]. In the era of massive automatization and IoT (Internet of Things), having a good technique for $\mathrm{CO}_{2}$ determination is a necessity [3]. Historically, $\mathrm{CO}_{2}$ sensors first appeared in the 1950's [1]. There are several principles of work of $\mathrm{CO}_{2}$ sensors: some measure pH-value (indirect and possibly inaccurate), some use gas chromatography and mass spectrometers (very expensive) etc. In this paper we will focus on NDIR type (nondispersive infrared) of $\mathrm{CO}_{2}$ sensors, since we believe that they are the best choice for automatic control, IoT and many other purposes. Figure 1 shows the principle of work of NDIR $\mathrm{CO}_{2}$ sensor [2].

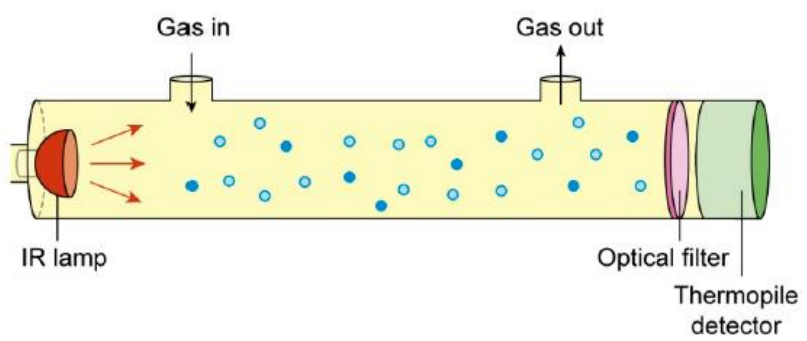

Fig. 1. Principle of work of NDIR sensor [2] 
Since $\mathrm{CO}_{2}$ has resonant frequencies in infrared (IR) part of the spectrum, construction of the NDIR $\mathrm{CO}_{2}$ sensor can be based on low-cost IR diode as source and some type of optical detector. Together with electronics and gas inlet (or diffusion membrane), entire sensor is usually small (few $\mathrm{cm}$ in size) and very affordable.

Calibration of $\mathrm{CO}_{2}$ sensors is usually performed by factory, which may be good enough for some applications. But in many cases professional (and potentially expensive) individual sensor calibration is required [4], [5]. There are dual channel NDIR $\mathrm{CO}_{2}$ sensors where one channel contains reference gas (usually nitrogen). Such sensors should be more accurate in the long run. The aim of this paper is to evaluate performance of several commercial $\mathrm{CO}_{2}$ sensors, with focus on one question: are they good enough for indoor air quality assessment?

\section{Sensors}

We have acquired several NDIR sensors, and they are described in Table 1. Amphenol Telaire is a single channel sensor with patented factory calibration algorithm, which requires periodical exposure of the sensor to the outdoor levels of $\mathrm{CO}_{2}$ (about $400 \mathrm{ppm}$ ). Plantower offers dual channel sensor for similar price, while Alphasense offers cell of the sensor and transmitter board separately. Price of the Alphasense sensor and the board is much higher than Amphenol and Plantower sensors. We should also note that Alphasense board doesn't provide digital signal (except USB), which means that additional circuitry is necessary to translate DC current into digital signal, if the sensor is connected to microcontroller, such as Raspberry Pi or Arduino. All sensors were successfully integrated into our in-house developed ecosystem for data acquisition, which was primarily developed for use in drones and later adapted for other applications as well [6], [7], [8].

\begin{tabular}{|c|c|c|c|}
\hline Sensor & Amphenol Telaire 6703 & Plantower DS-CO2-20 & Alphasense IRC-A1 (with board) \\
\hline & & & \\
\hline Type & Single channel NDIR & Dual Channel NDIR & Dual Channel NDIR \\
\hline Range & 2000 ppm & 5000 ppm & 5000 ppm \\
\hline Interface & Digital: UART and PWM & Digital: UART and PWM & Analog: 4-20 mA and USB \\
\hline
\end{tabular}

\section{Results}

Table 1. Description of sensors

The sensors were collocated in the Physics laboratory at the Faculty of Mechanical Engineering in Sarajevo for several months, during the summer semester 2019. The room has area of about $80 \mathrm{~m}^{2}$ and height $4 \mathrm{~m}$, giving total volume of 320 $\mathrm{m}^{3}$. It was periodically occupied with groups of 25 students (and 2 staff members).

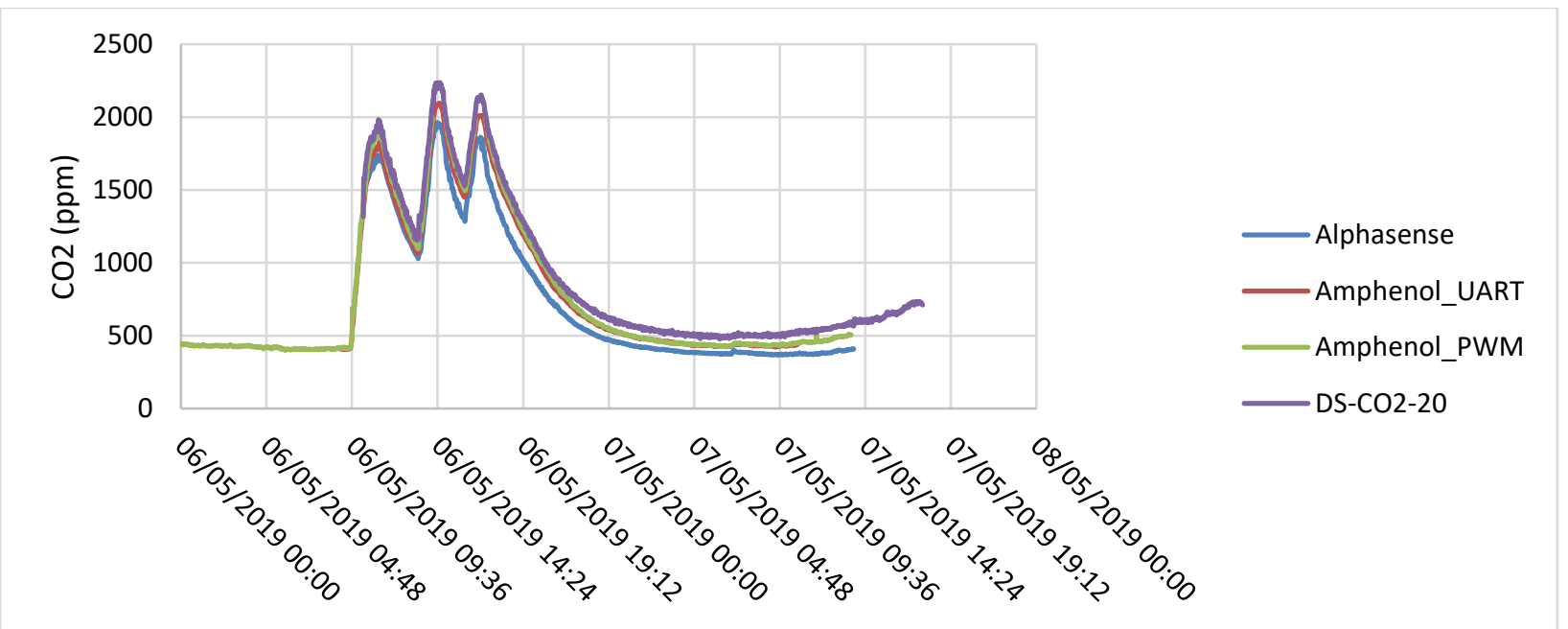

Fig. 2. Results for periodic occupation of the room 
Figure 2 shows readings from two Amphenol, one Alphasense and one Plantower sensor for a period of few days where the laboratory was occupied three times, corresponding to three peaks on the graph. We can see very good agreement among sensors. Alphasense was giving slightly lower values, while Plantower was giving highest readings, but the difference is acceptable. Peak values of $\mathrm{CO}_{2}$ concentration exceeded $2000 \mathrm{ppm}$.

Figure 3 shows fast build up and slow decay (without forced ventilation) some days later. Concentration of $\mathrm{CO} 2$ reached 3000 ppm. We can see some noise (spikes) in the Figure 3, which is a consequence of direct sunlight reaching the sensors, which must be prevented for valid measurements. Again, agreement among sensors is good, with Alphasense giving lower values.

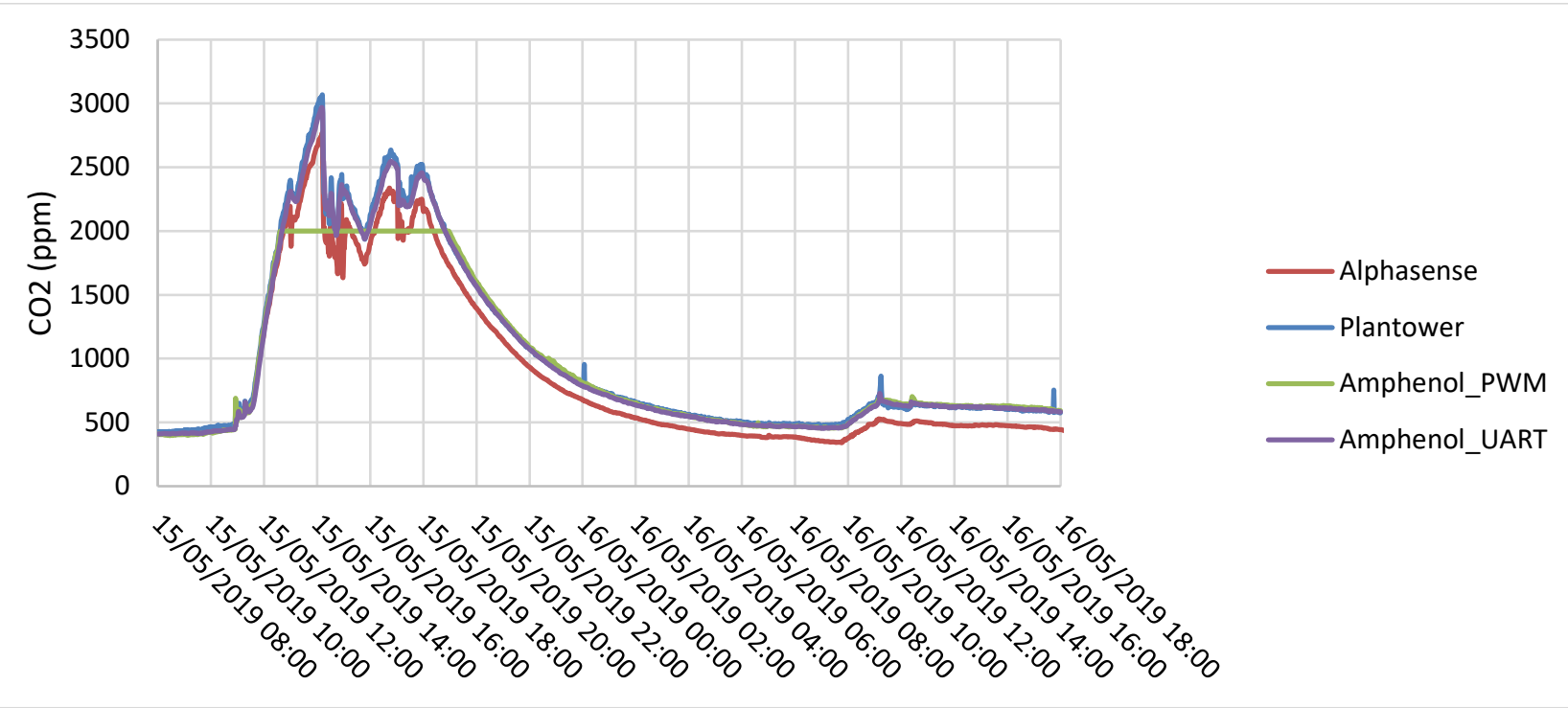

Fig. 3. Fast build up and slow decay of $\mathrm{CO}_{2}$ concentration

\section{Conclusion}

$\mathrm{CO}_{2}$ measurements in this study were successful with surprisingly good agreement among sensors (without any external calibration). Thus we can conclude that the latest generation of low-cost $\mathrm{CO}_{2}$ sensors is good enough to be used for indoor air quality assessment. We recommend dual-channel $\mathrm{CO}_{2}$ sensors with digital interface (UART or PWM). It is difficult to recommend Alphasense $\mathrm{CO}_{2}$ sensor and transmitter board for IoT applications, since it is expensive, bulky, and analog-interfaced. The range of $2000 \mathrm{ppm}$ (default value for many commercial $\mathrm{CO}_{2}$ sensors) is not sufficient for all indoor applications, and we recommend at least $5000 \mathrm{ppm}$ range. Proper enclosure for sensors is required, since the direct sunlight affects the measurements. As a suggestion for future work, we will try to measure $\mathrm{CO}_{2}$ outdoors, which will be much more challenging task. Network of multi point $\mathrm{CO}_{2}$ sensors connected over the internet is yet another proposal for future work.

\section{References}

[1] Neethirajan, S., Jayas, D. S. \& Sadistap, S. (2009). Carbon dioxide $\left(\mathrm{CO}_{2}\right)$ sensors for the agri-food industry - a review. Food and Bioprocess Technology, 2:115-121, 2009, DOI: 10.1007/s11947-008-0154-y

[2] Mendes, L. B. et al. (2015). NDIR Gas Sensor for Spatial Monitoring of Carbon Dioxide Concentrations in Naturally Ventilated Livestock Buildings, Sensors, 15, 11239-11257, 2015, DOI: 10.3390/s150511239

[3] Yasuda, T., Yonemura, S. \& Tani A. (2012). Comparison of the Characteristics of Small Commercial $\mathrm{NDIR}_{2} \mathrm{CO}_{2}$ Sensor Models and Development of a Portable $\mathrm{CO}_{2}$ Measurement Device, Sensors, 12, 3641-3655, 2012, DOI: $10.3390 / \mathrm{s} 120303641$

[4] Cho, H. C. \& Yi, S. H. (2010). NDIR $\mathrm{CO}_{2}$ gas sensor with improved temperature compensation. Procedia Engineering 5:303-306, 2010, DOI: 10.1016/j.proeng.2010.09.108

[5] Kim, J.H., Park H. G. \& Yi S. H. (2018). IR Absorbance as a Criterion for Temperature Compensation in Nondispersive Infrared Gas Sensor. Proceedings. 2018, DOI: 10.3390/proceedings 2130775

[6] Masic, A. (2015). Unmanned Aerial Vehicle as Data Acquisition System. Journal of Trends in the Development of Machinery and Associated Technology. Vol. 19, No. 1, 2015, ISSN 2303-4009 (online), p.p. 181-184.

[7] Masic, A.; Musemic, R. \& Dzaferovic-Masic, E. (2016). Temperature Inversion Measurements in Sarajevo Valley Using Unmanned Aerial Vehicles, Proceedings of the 27th DAAAM International Symposium, pp.0423-0427, B. Katalinic (Ed.), Published by DAAAM International, ISBN 978-3-902734-08-2, ISSN 1726-9679, Vienna, Austria, DOI: $10.2507 / 27$ th.daaam.proceedings.062

[8] Masic, A.; Bibic, Dz.; Pikula, B.; Dzaferovic-Masic, E. \& Musemic, R. Experimental study of temperature inversions above urban area using unmanned aerial vehicle. Thermal Science, 2018, DOI: 10.2298/TSCI180227250M 